\title{
Spontaneous Rectus Sheath Hematoma due to Low-Molecular-Weight Heparin Use: Case Series
}

\author{
Sinem Dogruyol' ${ }^{1 D}$, Fatma Sari Dogan² (D), Sinem Avci ${ }^{3}$ (D) \\ 'Department of Emergency Medicine, Tunceli Government Hospital, Tunceli, Turkey \\ 2Department of Emergency Medicine, Kartal Dr. Lutfi Kirdar Training and Research Hospital, Istanbul, Turkey \\ ${ }^{3}$ Department of Emergency Medicine, Ankara Training and Research Hospital, Ankara, Turkey
}

Cite this article as: Dogruyol S, Sari Dogan F, Avci S. Spontaneous Rectus Sheath Hematoma due to Low-Molecular-Weight Heparin Use: Case Series. Eurasian J Emerg Med. 2018; 17: 75-7.

\begin{abstract}
Rectus sheath hematoma (RSH) is one of the reasons for acute abdominal pain in patients using low-molecular-weight heparin. The diagnosis can be confused with other diseases or even can be missed if not brought to notice. RSH may be fatal in the case of misdiagnosis or delayed treatment. Therefore, these cases are specific for emergency medicine practices. Recent studies and case series about RSH were mostly published by general surgery clinics. Emergency department is the first place where patients with RSH visit. However, limited case reports from the emergency departments have been published. This study highlights the importance of diagnosis and proper management of rectus hematomas in emergency clinics in the light of the three presented cases.
\end{abstract}

Keywords: Anticoagulant therapy, emergency medicine, low-molecular-weight heparin, rectus sheath hematoma

\section{Introduction}

Rectus sheath hematoma (RSH) is a clinical entity characterized by the presence of blood within rectus abdominis muscle sheath. It may be caused by damaged epigastric vessels or rectus muscle (1). It may occur either spontaneously or because of trauma, abdominal surgery, sudden physical exercise, pregnancy, or subcutaneous injection.

Low-molecular-weight heparins (LMWHs) are increasingly being used both in community and in hospital settings. They are easy to administer and have an improved bioavailability, and there is no need to monitor anticoagulation (2). However, the risk of causing lethal complications in terms of bleeding has to be ruled out. Moreover, cases of RSH associated with subcutaneous injection of LMWHs have been reported (3).

Rectus sheath hematoma is generally considered to be a self-limiting condition but may be fatal in some cases (4). This study reported three cases with $\mathrm{RSH}$ receiving anticoagulant therapy; one of them turned out to be fatal.

\section{Case Presentations}

\section{Case 1}

A 56-year-old female patient visited the emergency service with complaints of nausea and fatigue. Her medical history showed that she was under a routine hemodialysis program due to chronic kidney disease. She had been using 60-mg enoxaparin sodium subcutaneously for atrial fibrillation. A physical examination revealed that her blood pressure was $110 / 60 \mathrm{mmHg}$ and her pulse rate was 98 beats/min. Also, a palpable mass and sensitivity were detected in the left lower quadrant of her abdomen, whereas other system examinations were normal. Subcutaneous LMWHs were also administered into her abdominal region. The electrocardiography of the patient was compatible with atrial fibrillation. Laboratory results showed that her hemoglobin was 8 (12.016.0) $\mathrm{g} / \mathrm{dL}$, which was $2 \mathrm{~g} / \mathrm{dL}$ less than the previously detected level, but her other laboratory results were found to be normal. No abnormality was observed in her coagulation parameters. The intravenous contrastenhanced computed tomography (CT) of the patient revealed the presence of an RSH in the left lower quadrant (Figure 1a). The patient was transferred to the general surgery service for further follow-up.

ORCID IDs of the authors: S.D. 0000-0002-6949-7233; F.S.D. 0000-0002-3790-9774; S.A. 0000-0002-2294-602X. 


\section{Case 2}

A 66-year-old female patient with a poor general condition visited the emergency service with complaints of nose bleeding and stomach ache. Her medical history showed that she earlier had a brain stroke. She had been treated with subcutaneous enoxaparin sodium ( $80 \mathrm{mg} /$ day) and oral warfarin sodium ( $5 \mathrm{mg} /$ day) for her immobilization-related deep-vein thrombosis (DVT) prophylaxis. The physical examination revealed that her blood pressure was $103 / 61 \mathrm{mmHg}$ and her pulse rate was $89 / \mathrm{min}$; a palpable mass and sensitivity were detected in the left lower quadrant of her abdomen. The electrocardiography of the patient was compatible with atrial fibrillation. Her laboratory results indicated that the hemoglobin level was 9.1 (normal range, 12.0-16.0) g/dL, number of thrombocytes was 150,000 (normal range, 150,000-450,000) $/ \mathrm{mm}^{3}$, activated partial thromboplastin time was 46.1 (normal range, 22.6-35) $\mathrm{s}$, prothrombin time was $16.5 \mathrm{~s}$ (normal range, 11.4-15.5 s), and the international normalization ratio (INR) was 1.32 (normal range, 0.81.25). Other laboratory parameters were found to be normal. In terms of diagnosis and treatment decision for stomach ache complaints, an intravenous contrast-enhanced abdominal CT was planned. The CT of the patient showed a view compatible with the RSH in the left lower quadrant (Figure 1b). The patient was transferred to the general surgery service for further follow-up. The patient was died on the first day of her hospitalization due to hypovolemic shock related cardiopulmonary arrest.

\section{Case 3}

A 73-year-old male patient was brought to the emergency service by his relatives because of his poor general condition. His medical history showed that he was diagnosed with chronic hypertension and diabetes mellitus. Also, he was operated for a hip fracture 3 weeks ago. The patient, who was on bed rest, had been using 80mg enoxaparin sodium subcutaneously twice a day for his DVT prophylaxis. A physical examination of the patient showed that he had a poor overall condition and looked pale. In addition, his blood pressure was $70 / 40 \mathrm{mmHg}$ and pulse rate was $130 / \mathrm{min}$. His physical examination showed severe abdominal sensitivity and an ecchymosis of $10 \times 10 \mathrm{~cm}^{2}$ surrounding the right lower and upper quadrants. His electrocardiography was compatible with sinus tachycardia. Laboratory results revealed that his hemoglobin was 6.4 (normal range, $12.0-16.0) \mathrm{g} / \mathrm{dL}$, and the number of thrombocytes was 120,000 (normal range, $150,000-450,000$ ) $/ \mathrm{mm}^{3}$. Other laboratory parameters were found to be normal. No abnormalities in coagulation parameters were observed. The CT of the patient showed a view compatible with $\mathrm{RSH}$ in the right quadrant extending through the upper quadrant of the abdomen (Figure 2a and b). During the emergency follow-up, two units of erythrocyte suspension and two units of fresh-frozen plasma were replaced. At the end of the fourth hour, his blood pressure was $120 / 70 \mathrm{mmHg}$ and his pulse rate was $100 / \mathrm{min}$. He was transferred to the general surgery service with stable vital findings.

\section{Discussion}

Rectus sheath hematoma usually starts with a sudden stomach ache and mimics acute abdominal cases (5). However, the diagnosis is not easy in invalid patients with misleading anamnesis. Only one patient reported stomachache in this study. Therefore, a detailed and careful physical examination is more important than only anamnesis in such patients.
Rectus sheath hematoma may be associated with trauma, surgery, sudden coughing-related muscle contraction, abdominal injections, and pregnancy; it may also occur by itself. Moreover, many risk factors, such as anticoagulant treatment, advanced age, central obesity, female sex, coagulation disorders, and kidney failure, may also trigger the development of RSH $(6,7)$. Two of the cases in this study included females, and both of them had chronic kidney disease. Moreover, all three cases had been treated with anticoagulants. In terms of localization, most of the RSH cases occur in the lower abdominal quadrant (80\%) and on the right side (60\%) of the abdomen (8). Unlike the cases reported in the literature, hematomas in two of the presented cases were localized to the left side, whereas the hematoma in one case was localized to the right side. However, hematomas in all cases were localized in the lower quadrants of the abdomen.

Currently, a large number of patients use LMWHs, and the frequency of their preference is increasing because of the high bioavailability and few side effects of LMWHs. Furthermore, LMWHs can be used for prophylaxis and treatment of diseases such as DVT and pulmonary embolism even out of the hospital (9). Complication rates and RSH occurrence rates have increased because of the common use of LMWHs (10). Also, the three cases in the present study had been using subcutaneous enoxaparin. Similar to the study by Adeonigbagbe et al. (11), one of the cases with RSH had been using enoxaparin and warfarin for DVT prophylaxis; only the INR was different. In addition to the anticoagulant effect, subcutaneous LMWH administration in the abdominal region might have triggered $\mathrm{RSH}$ in the present study.

Two visualization techniques are used in the diagnosis of RSH: ultrasonography and CT. Although ultrasonography is not as

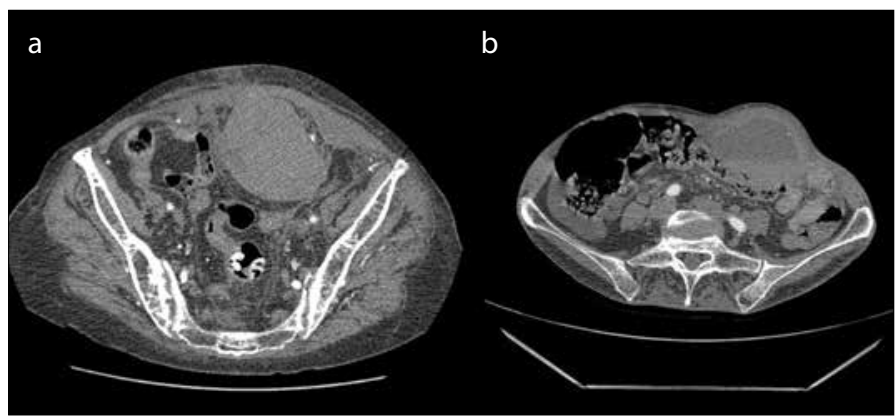

Figure 1. a, b. (a) Axial CT image of a left RSH; (b) Axial CT image of complex fluid collection with layering consistent with hematoma RSH: rectus sheath hematoma; CT: computed tomography

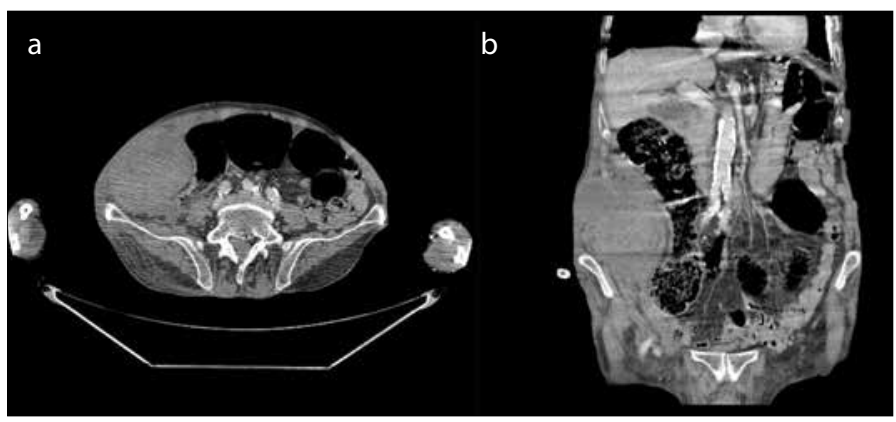

Figure 2. a, b. (a) Axial CT image of a right $\mathrm{RSH}$; (b) Coronal $\mathrm{CT}$ image of a right $\mathrm{RSH}$ with extension in the lateral abdominal wall RSH: rectus sheath hematoma; CT: computed tomography 
sensitive as CT, it is preferred because of its speed and noninvasiveness. However, computed abdominal tomography is used as a gold-standard diagnostic tool in non-diagnostic ultrasonography, elimination of other intra-abdominal pathologies, and classification of RSH. Its sensitivity and specificity are $100 \%$ (12). All cases in the present study were examined by intravenous-contrasted abdominal $\mathrm{CT}$ for an accurate treatment decision.

For treatment, it is recommended to cut down anticoagulant medications, replace blood products, bring coagulation parameters within a normal range, and eliminate risk factors (13). All of the cases were closely followed-up, and a blood product replacement was performed by examining their vital parameters.

A patient that did not undergo transfusion in the emergency service due to hemodynamic stabilization had a disruption in her coagulation parameters and was lost because of a cardiopulmonary arrestdependent hypovolemic shock on the first day of hospitalization. Unlike the cases reported in the literature, fresh-frozen plasma may be given to a patient with small disruptions in the coagulation values, even in hemodynamically stable cases. Because of a limited number of case series in emergency clinics, enough information is not available in the literature that blood product transfusion recovers the prognosis of these cases on their first visit.

Large or complicated hematomas may require surgical treatment in cases with hemodynamic instability (14). None of the cases in the present study underwent surgery, and some conservative treatment options were followed for them. One case was lost during the followup.

\section{Conclusion}

The frequency of RSH is on a continuous rise in elderly patients, patients undergoing anticoagulant treatment, and patients requiring special care. Emergency department is the first place where patients visit and are diagnosed for RSH. Therefore, emergency physicians should carefully examine the patients presenting with a stomachache, poor overall condition, anemia, or a palpable mass in their abdomen.

Subcutaneous use of LMWHs increases the frequency of RSH. Besides health care professionals, patients and their relatives should be wellinformed about the circumstances, especially when they inject themselves. Since subcutaneous lipid tissue injections are risky, the deltoid site should be preferred especially for thin patients. The use of LMWHs should not be considered as a totally safe treatment because of its anticoagulant effect; both the patient and the physician should be careful about this treatment.

Informed Consent: Written informed consent was obtained from patients/ patients' relatives who participated in this 'case series'.
Peer-review: Externally peer-reviewed.

Author Contributions: Concept - S.D.; Design - F.S.D.; Supervision - F.S.D.; Resources - S.A.; Data Collection and/or Processing - S.D., F.S.D.; Analysis and/ or Interpretation - S.A.; Literature Search - S.A.; Writing Manuscript - S.D.; Critical Review - S.A.

Conflict of Interest: The authors have no conflict of interest to declare.

Financial Disclosure: The authors declared that this study has received no financial support.

\section{References}

1. Akturk OM, Kayilioglu, SI, Aydogan I, Dinc T, Yildiz B, Cete M, et al. Spontaneous rectus sheath hematoma: an overview of 4-Year single center experience. Indian J Surg. 2015; 77: 1219-21. [CrossRef]

2. Donaldson J, Knowles CH, Clark SK, Renfrew I, Lobo MD. Rectus sheath haematoma associated with low molecular weight heparin: a case series. Ann R Coll Surg Engl. 2007; 89: 309-12. [CrossRef]

3. Sullivan LEJ, Wortham DC, Litton KM. Rectus sheath hematoma with low molecular weight heparin administration: a case series. BMC Res. Notes 2014; 7: 586. [CrossRef]

4. Jafferbhoy SF, Rustum Q, Shiwani MH. Abdominal compartment syndrome - a fatal complication from a rectus sheath haematoma. BMJ Case Rep. 2012; bcr1220115332.

5. Eckhoff K, Wedel T, Both M, Bas K, Maass N, Alkatout l, et al. Spontaneous rectus sheath hematoma in pregnancy and a systematic anatomical workup of rectus sheath hematoma: a case report. J Med Case Rep. 2016; 10: 292. [CrossRef]

6. Cherry WB, Mueller PS. Rectus sheath hematoma: review of 126 cases at a single institution. Medicine (Baltimore). 2006; 85: 105-10. [CrossRef]

7. Anyfantakis D, Kastanakis M, Petrakis G, Bobolakis E. Rectus sheath hematoma in a single secondary care institution: a retrospective study. Hernia. 2015; 19:509-512. [CrossRef]

8. Golcuk Y, Oray D, Bademkiran E. Type III rectus sheath hematoma: a case report. Turk J Emerg Med. 2012; 12: 38-41. [CrossRef]

9. Akdeniz B, Turker S, Aslan YO, Guneri S. Rectus Sheath Hematoma in Patients Undergoing Low Molecular Weight Heparin Therapy: 3 Case Reports and Review of the Literature. Archives of the Turkish Society of Cardiology. 2002; 30: 313-6.

10. Holmes SJ, Yale SH, Mazza JJ. Rectus sheath hematoma as a cause of acute abdominal pain. Am Fam Physician. 2001; 64: 1681-2.

11. Adeonigbagbe $O$, Khademi $A$, Karowe $M$, Gualtieri $N$, Robilotti J. Spontaneous rectus sheath hematoma and an anterior pelvic hematoma as a complication of anticoagulation. Am J Gastroenterol. 2000; 95: 314-5. [CrossRef]

12. Fitzgerald JE, Fitzgerald LA, Anderson FE, Acheson AG. The changing nature of rectus sheath haematoma: case series and literature review. Int J Surg. 2009; 7: 150-4. [CrossRef]

13. Vanpee D, Gillet JP. Rectus sheath hematoma. Ann Emerg Med. 2000; 36: 78. [CrossRef]

14. Zengin K, Carkman S, Kilic I, Beken E, Eyuboglu E. Treatment apporoaches to rectus sheath hematoma. Ulus Travma Acil Cerrahi Derg. 2007; 13: 55-9. 